\title{
The Effectiveness of Strengthening of Hip Extensors and Ankle Plantar Flexors in Early Post-Anterior Cruciate Ligament Reconstruction
}

\author{
AHMED M. GAD, M.Sc.*; NADIA A. FAYAZ, Ph.D.**; KARIMA A. HASSAN, Ph.D.** and \\ MOHAMMAD H. AHMAD, M.D.*** \\ The Department of Physical Therapy, El-Hadra University Hospital, Alexandria*, The Department of Physical Therapy for \\ Musculoskeletal Disorders**, Faculty of Physical Therapy, Cairo University and The Department of Orthopedic Surgery***, \\ Faculty of Medicine, Alexandria University, Egypt
}

\begin{abstract}
Background: Impaired hip strength may underlie abnormal movement patterns, suggesting that diminished hip strength may increase the risk of ACL injury and re injury after anterior cruciate ligament reconstruction.

Aim of Study: To investigate the effect of strengthening of hip extensors and ankle plantar flexors in early Anterior Cruciate Ligament reconstruction on knee effusion, knee function, hip, knee and ankle muscles strength.

Methods: The study was conducted on 30 male patients referred from the orthopedic surgeon with early post operative Anteior Cruciate Ligament reconstruction by hamstring graft or patellar tendon graft after acute injuries, their age range from 18-40 years and were randomly assigned into two groups. Group A: Consisted of fifteen patients who had received open kinetic chain strengthening exercises for hip extensors and ankle plantar flexors in addition to the traditional accelerated program. Group B: Consisted of fifteen patients who had received the traditional accelerated program for 6 weeks (three sessions per week), effusion grading scale for effusion to assess effusion, handheld dynamometer to assess muscle power, Westen Ontario and MACmaster universities score and Time Up and Go test for functional assessment.

Results: There was no significant difference between both groups for, hip extensors force and (TUG at 3 weeks). There was no significant difference between both groups for knee extensors torque between base line and 3 weeks and the same for plantar flexors force and WOMAC at 3 weeks. There was significant difference between both groups for knee extensors torque between 3 and 6 weeks, WOMAC at 6 weeks, TUG at 6 weeks and plantar flexors force between 3 and 6 weeks.
\end{abstract}

Conclusion: Adding strengthening exercises of hip extensors and plantar flexors to the traditional accelerated protocol added more beneficial outcomes in relation to function after 6 weeks.

Correspondence to: Dr. Ahmed M. Gad, The Department of Physical Therapy, El-Hadra University Hospital, Alexandria, Faculty of Physical Therapy, Cairo University
Key Words: ACLR - Rehabilitation - Accelerated programHip extensors and plantar flexors.

\section{Introduction}

INJURY to the anterior cruciate ligament (ACL) is associated with knee instability, altered knee joint loading and impaired neuromuscular control, defined as the ability to produce well controlled movements through coordinated muscle activity $[1,2]$. Anterior cruciate ligament reconstruction (ACLR) is often performed to reproduce the function of the original ligament and restore functional stability of the knee joint after ACL injury [3]

Jaramillo et al., (1994) [7] reported hip flexor and extensor and hip-abductor and adductor weakness after knee surgery, but their results were not limited to a population that had ACL reconstruction. The presence of both hip-flexor and adductor weakness has been confirmed after ACL reconstruction [8-10]. When the hip, ankle, and foot segments are not effective in synergistically reducing ground-reaction forces, the leg is converted into a 2-segment column, which may be incapable of adequately absorbing the energy from the ground reaction forces [11]

The accelerated rehabilitation protocol is based on scientific evidence regarding complications such as graft elongation or rupture. An optimal rehabilitation program includes preoperative patient education and training to create a realistic view, enhance independence and facilitate an optimal timing of surgery [2,12-16]. The effect of an accelerated rehabilitation protocol with regard to the most used fixation methods (interference screws and endobutton) has been documented extensively $[15,17]$. 
Whether hip flexion in combination with a flatfooted position increases the axial forces on the knee with landing and deceleration, these findings may due to weakness in these muscles [11]

The current study may provide a more conclusive program for treatment the patients after ACL reconstruction, this program may be able to improve symptoms, shock absorption and weight bearing during functional activities, within a short period of time and may be more efficient than the conventional approach alone.

\section{Patients and Methods}

Upon approval of Cairo University's supreme council of postgraduate studies and research. The study was conducted on 30 male patients referred from orthopedic surgeon with early post ACL reconstruction by hamstring graft or patellar tendon graft after acute injuries, their age range from 1840 years and each subject was examined by the researcher for the inclusive and exclusive criteria were randomly assigned into two groups. All patients participating in the study were signed an informed consent form. This study was conducted at the outpatient clinic at El-Hadra University Hospital at Alexandria. The study extended from October 2017 to March 2018.

Group A: Consisted of fifteen patients who had received open kinetic chain strengthening exercises for hip extensors and open kinetic chain exercises for ankle plantar flexors in addition to traditional accelerated program (faradic stimulation, ice, quadriceps drill exercises, hamstring drill exercises, short arc knee extension, hamstring curl exercise, knee slide and straight leg raising) for 6 weeks (three sessions per week).

Group B: Consisted of fifteen patients who had received traditional accelerated program for 6 weeks (three sessions per week), and both groups were assessed for effusion (effusion grading scale at base line, after 3 weeks and after 6 weeks) WOMAC (The Western Ontario and McMaster Universities) Score (Appendix I) and Timed Up and Go test (TUG) for function at 3 weeks and 6 weeks and the assessment of hip extensors muscles force, plantar flexors muscles force and knee extensors torque by hand held dynamometer at base line, after 3 weeks and after 6 weeks (Appendix II).

\section{Statistical analysis:}

Descriptive statistics and $t$-test was conducted for comparison of the subject characteristics between both groups. Mixed MANOVA was conducted to compare the effect of time and the effect of treatment, as well as the interaction between time and treatment on mean values of TUG, WOMAC, hip extensors force, knee extensors torque and ankle planter flexors force. The level of significance for all statistical tests was set at $p<0.05$. All statistical measures were performed through the statistical package for social studies (SPSS) version 19 for windows.

\section{Results}

General characteristics of the subjects in both groups for their mean \pm SD age, weight, height and BMI were shown in Table (1).

Table (1): Descriptive statistics and $t$-test for comparing the mean age, weight, height and BMI of group A and B.

\begin{tabular}{lclllll}
\hline & $\begin{array}{c}\text { Group A } \\
\mathrm{X} \pm \mathrm{SD}\end{array}$ & $\begin{array}{c}\text { Group B } \\
\mathrm{X} \pm \mathrm{SD}\end{array}$ & $\mathrm{MD}$ & $t$-value & $p$-value & Sign \\
\hline Age (years) & $24.61 \pm 5.78$ & $26.38 \pm 5.47$ & -1.77 & -0.8 & 0.43 & $\mathrm{NS}$ \\
Weight $(\mathrm{kg})$ & $85.61 \pm 11.02$ & $81.07 \pm 11.09$ & 4.54 & 1.04 & 0.3 & $\mathrm{NS}$ \\
Height $(\mathrm{cm})$ & $177.15 \pm 6.33$ & $174.07 \pm 6.66$ & 3.08 & 1.2 & 0.23 & $\mathrm{NS}$ \\
BMI $\left(\mathrm{kg} / \mathrm{m}^{2}\right)$ & $27.23 \pm 2.62$ & $26.66 \pm 2.35$ & 0.57 & 0.58 & 0.56 & $\mathrm{NS}$ \\
\hline $\mathrm{X}:$ Mean. & MD : Mean difference. & $p$-value: Probability value. \\
SD : Standard deviation. & $t$-value : Unpaired $t$-value. & NS : Non significant.
\end{tabular}

\section{Effect of treatment on effusion grading scale:}

There was a significant improvement in the effusion grading scale at 3 weeks in group A compared with that at base line $(p=0.0001)$. There was a significant improvement in the effusion grading scale at 6 weeks compared with that at base line $(p=0.0001)$. There was a significant improvement in the effusion grading scale at 6 weeks compared with that at 3 weeks $(p=0.006)$ (Table 2).
There was a significant improvement in the effusion grading scale at 3 weeks in group B compared with that at base line $(p=0.0001)$. There was a significant improvement in the effusion grading scale at 6 weeks compared with that at base line $(p=0.0001)$. There was a significant improvement in the effusion grading scale at 6 weeks compared with that at 3 weeks $(p=0.002)$ (Table 3). 
Table (2): Frequency distribution and marginal homogeneity test for comparison of effusion grading scale between base line, 3 and 6 weeks in group A.

\begin{tabular}{lllllr}
\hline $\begin{array}{l}\text { Effusion grading } \\
\text { scale }\end{array}$ & Base line & 3 weeks & MH Statistic & $p$-value & Sig. \\
\hline Trace & $0(0 \%)$ & $8(53 \%)$ & 38.5 & 0.0001 & $\mathrm{~S}$ \\
$1^{+}$ & $2(13 \%)$ & $4(27 \%)$ & & & \\
$2^{+}$ & $4(27 \%)$ & $3(20 \%)$ & & & \\
$3^{+}$ & $9(60 \%)$ & $0(0 \%)$ & & & \\
\hline & Base line & 6 weeks & MH Statistic & $p$-value & Sig. \\
\hline 0 & $0(0 \%)$ & $5(33 \%)$ & 31.5 & 0.0001 & $\mathrm{~S}$ \\
Trace & $0(0 \%)$ & $9(60 \%)$ & & & \\
$1+$ & $2(13 \%)$ & $1(7 \%)$ & & & \\
$2^{+}$ & $4(27 \%)$ & $0(0 \%)$ & & & \\
$3^{+}$ & $9(60 \%)$ & $0(0 \%)$ & & & \\
\hline & 3 weeks & 6 weeks & MH Statistic & $p$-value \\
\hline 0 & $0(0 \%)$ & $5(33 \%)$ & & 15 & \\
Trace & $8(53 \%)$ & $9(60 \%)$ & & & \\
$1+$ & $4(27 \%)$ & $1(7 \%)$ & & & \\
$2+$ & $3(20 \%)$ & $0(0 \%)$ & & & \\
$3^{+}$ & $0(0 \%)$ & $0(0 \%)$ & & & \\
\hline MH: Marginal homogeneity test value & $p$-value: Probability value. S: Significant.
\end{tabular}

Table (3): Frequency distribution and marginal homogeneity test for comparison of effusion grading scale between base line, 3 and 6 weeks in group B.

\begin{tabular}{lllccc}
\hline $\begin{array}{l}\text { Effusion grading } \\
\text { scale }\end{array}$ & Base line & 3 weeks & MH Statistic & $p$-value & Sig. \\
\hline Trace & $0(0 \%)$ & $5(33 \%)$ & 40 & 0.0001 & $\mathrm{~S}$ \\
$1^{+}$ & $0(0 \%)$ & $7(47 \%)$ & & & \\
$2+$ & $8(53 \%)$ & $3(20 \%)$ & & & \\
$3^{+}$ & $7(47 \%)$ & $0(0 \%)$ & & & \\
\hline & Base line & 6 weeks & MH Statistic & $p$-value & Sig. \\
\hline 0 & $0(0 \%)$ & $4(27 \%)$ & 32 & 0.0001 & $\mathrm{~S}$ \\
Trace & $0(0 \%)$ & $10(66 \%)$ & & & \\
$1+$ & $0(0 \%)$ & $1(7 \%)$ & & & \\
$2^{+}$ & $8(53 \%)$ & $0(0 \%)$ & & & Sig. \\
$3^{+}$ & $7(47 \%)$ & $0(0 \%)$ & & & \\
\hline & 3 weeks & 6 weeks & MH Statistic & & \\
\hline 0 & $0(0 \%)$ & $4(27 \%)$ & 15 & & \\
Trace & $5(33 \%)$ & $10(66 \%)$ & & & \\
$1^{+}$ & $7(47 \%)$ & $1(7 \%)$ & & & \\
$2^{+}$ & $3(20 \%)$ & $0(0 \%)$ & & & \\
$3^{+}$ & $0(0 \%)$ & $0(0 \%)$ & & & \\
\hline
\end{tabular}

MH: Marginal homogeneity test value. $\quad p$-value: Probability value. S: Significant.

There was no significant difference in effusion grading scale between group A and B at base line, 3 weeks and at 6 weeks (Table 4).

\section{Effect of treatment on TUG:}

There was a significant decrease in TUG score in group A at 6 weeks compared with that at 3 weeks $(p=0.0001)$. There was a significant decrease in TUG score in group B at 6 weeks compared with that at 3 weeks $(p=0.0001)$. Multiple pairwise comparison showed that there was no significant differ- ence in the mean values of TUG score at 3 weeks between group $\mathrm{A}$ and $\mathrm{B}(p=0.06)$. However, there was a significant decrease in the mean values of the TUG score of the group A post treatment compared with that of group B $(p=0.002)$ (Table 5).

\section{Effect of treatment on WOMAC:}

There was a significant decrease in WOMAC score in group A at 6 weeks compared with that at 3 weeks $(p=0.0001)$. There was a significant decrease in WOMAC score in group B at 6 weeks 
compared with that at 3 weeks $(p=0.0001)$. Multiple pairwise comparison showed that there was no significant difference in the mean values of WOMAC score at 3 weeks between group A and B $(p=0.22)$. However, there was a significant decrease in the mean values of the WOMAC score of the group A post treatment compared with that of group B $(p=0.009)$ (Table 6).

Table (4): Frequency distribution and chi-squared test for comparison of effusion grading scale at base line, 3 and 6 weeks between group A and B.

\begin{tabular}{lllllr}
\hline $\begin{array}{l}\text { Effusion grading scale } \\
\text { Base line }\end{array}$ & Group A & Group B & $\chi^{2}$ & $p$-value & Sig. \\
\hline $1+$ & $2(13 \%)$ & $0(0 \%)$ & 3.58 & 0.16 & $\mathrm{NS}$ \\
$2+$ & $4(27 \%)$ & $8(53 \%)$ & & & \\
$3^{+}$ & $9(60 \%)$ & $7(47 \%)$ & & & Sig. \\
\hline 3 weeks & Group A & Group B & $\chi^{2}$ & $p$-value & S \\
\hline Trace & $8(53 \%)$ & $5(33 \%)$ & 1.51 & 0.47 & \\
$1+$ & $4(27 \%)$ & $7(47 \%)$ & & & Sig. \\
$2+$ & $3(20 \%)$ & $3(20 \%)$ & & & NS \\
\hline 6 Weeks & Group A & Group B & $\chi^{2}$ & $p$-value & \\
\hline 0 & $5(33 \%)$ & $4(27 \%)$ & 0.16 & 0.92 & \\
Trace & $9(60 \%)$ & $10(66 \%)$ & & & \\
$1+$ & $1(7 \%)$ & $1(7 \%)$ & & & \\
\hline$\chi 2:$ Chi squared value. & $p$-value: Probability value. S: Significant. & & \\
& & & & & \\
\hline
\end{tabular}

Table (5): Mean TUG score at 3 and 6 weeks of group A and B.

\begin{tabular}{lllllll}
\hline TUG $(\mathrm{sec})$ & $\begin{array}{l}3 \text { weeks } \\
\mathrm{X} \pm \mathrm{SD}\end{array}$ & $\begin{array}{l}\text { 6 weeks } \\
\mathrm{X} \pm \mathrm{SD}\end{array}$ & MD & \% of change & $p$-value & Sig. \\
\hline Group A & $10.06 \pm 2.19$ & $6.89 \pm 1.04$ & 3.17 & 31.51 & 0.0001 & $\mathrm{~S}$ \\
Group B & $11.53 \pm 1.6$ & $8.43 \pm 1.2$ & 3.1 & 26.88 & 0.0001 & $\mathrm{~S}$ \\
MD & -1.47 & -1.54 & & & \\
$p$-value & 0.06 & 0.002 & & \\
Sig. & NS & $\mathrm{S}$ & & \\
\hline $\mathrm{X} \quad$ : Mean. & $p$-value: Probability value. \\
SD : Standard deviation. & S : Significant. \\
MD : Mean difference. & NS: Non significant. & & \\
&
\end{tabular}

Table (6): Mean WOMAC score 3 and 6 weeks of group A and B.

\begin{tabular}{|c|c|c|c|c|c|c|}
\hline WOMAC & $\begin{array}{l}3 \text { weeks } \\
X \pm S D\end{array}$ & $\begin{array}{l}6 \text { weeks } \\
X \pm S D\end{array}$ & MD & $\%$ of change & $p$-value & Sig. \\
\hline Group A & $33.3 \pm 12.75$ & $10.38 \pm 5.82$ & 22.92 & 68.82 & 0.0001 & S \\
\hline Group B & $38.69 \pm 9.12$ & $17.69 \pm 7.14$ & 21 & 54.27 & 0.0001 & S \\
\hline $\mathrm{MD}$ & -5.39 & -7.31 & & & & \\
\hline$p$-value & 0.22 & 0.009 & & & & \\
\hline Sig. & NS & $\mathrm{S}$ & & & & \\
\hline 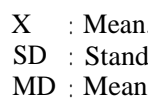 & $\begin{array}{l}\text { leviation. } \\
\text { erence. }\end{array}$ & $\begin{array}{l}p \text {-value: Probab } \\
\text { S : Significant } \\
\text { NS: Non signifi }\end{array}$ & $\begin{array}{l}\text { ty value. } \\
\text { nt. }\end{array}$ & & & \\
\hline
\end{tabular}

\section{Effect of treatment on hip extensors force:}

There was a significant increase in hip extensors force at 3 weeks compared with that at base line $(p=0.0001)$. There was a significant increase in hip extensors force at 6 weeks compared with that at base line $(p=0.0001)$. The mean difference in hip extensors force between 3 and 6 weeks was $2.9 \mathrm{~kg}$ and the percent of change was $13.78 \%$. There was a significant increase in hip extensors force at 6 weeks compared with that at 3 weeks $(p=0.01)$. There was a significant increase in hip extensors force at 3 weeks compared with that at base line $(p=0.007)$. There was a significant increase in hip extensors force at 6 weeks compared with that at base line $(p=0.0001)$. The mean difference in hip extensors force between 3 and 6 weeks was -3.21 
$\mathrm{kg}$ and the percent of change was $16 \%$. There was a significant increase in hip extensors force at 6 weeks compared with that at 3 weeks $(p=0.005)$.

Multiple pairwise comparison showed that there was no significant difference in the mean values of hip extensors force at base line between group $\mathrm{A}$ and $\mathrm{B}(p=0.19)$. Also, there was no significant difference in hip extensors force between groups at 3 and 6 weeks $(p<0.05)$ (Table 7$)$.

\section{Effect of treatment on knee extensors torque:}

There was a significant increase in knee extensors torque at 3 weeks compared with that at base line $(p=0.0001)$. There was a significant increase in knee extensors torque at 6 weeks compared with that at base line $(p=0.0001)$. There was a significant increase in knee extensors' force at 6 weeks compared with that at 3 weeks $(p=0.004)$. There was a significant increase in knee extensors force at 3 weeks compared with that at base line $(p=0.0001)$. There was a significant increase in knee extensors force at 6 weeks compared with that at base line $(p=0.0001)$. There was no significant difference in knee extensors force between 3 and 6 weeks $(p=0.1)$.

Multiple pairwise comparison showed that there was no significant difference in the mean values of knee extensors' force at base line between group $\mathrm{A}$ and $\mathrm{B}(p=0.37)$. Also, there was no significant difference in knee extensors force between groups at 3 and 6 weeks $(p<0.05)$ (Table 8).

Effect of treatment on ankle planter flexors force:

There was a significant increase in ankle planter flexors force at 3 weeks compared with that at base line $(p=0.002)$. There was a significant increase in ankle planter flexors force at 6 weeks compared with that at base line $(p=0.0001)$. There was a significant increase in ankle planter flexors force at 6 weeks compared with that at 3 weeks $(p=0.0001)$. There was no significant difference in ankle planter flexors force between base line and 3 weeks $(p=0.06)$. There was a significant increase in ankle planter flexors force at 6 weeks compared with that at base line $(p=0.0001)$. There was a significant increase in ankle planter flexors' force at 6 weeks compared with that at 3 weeks $(p=0.007)$.

Multiple pairwise comparison showed that there was no significant difference in the mean values of ankle planter flexors' force at base line between group $\mathrm{A}$ and $\mathrm{B}(p=0.85)$. Also, there was no significant difference in ankle planter flexors' force between groups at 3 and 6 weeks $(p<0.05)$ (Table 9).

Table (7): Mean hip extensors' force at base line, 3 and 6 weeks of group A and B.

\begin{tabular}{|c|c|c|c|c|c|}
\hline \multicolumn{6}{|c|}{ Hip extensors' force $(\mathrm{kg})$} \\
\hline \multicolumn{3}{|c|}{$\begin{array}{l}\text { Group A } \\
\mathrm{X} \pm \mathrm{SD}\end{array}$} & \multicolumn{3}{|c|}{$\begin{array}{c}\text { Group B } \\
\mathrm{X} \pm \mathrm{SD}\end{array}$} \\
\hline Base line & 3 weeks & 6 weeks & Base line & 3 weeks & 6 weeks \\
\hline $14.52 \pm 3.12$ & $21.03 \pm 5.42$ & $23.93 \pm 5.36$ & $16.85 \pm 5.4$ & $20.07 \pm 5.09$ & $23.28 \pm 2.95$ \\
\hline \multicolumn{6}{|c|}{ Within group comparison } \\
\hline & & MD & $\%$ of change & $p$-value & Sig. \\
\hline \multicolumn{6}{|l|}{ Group A: } \\
\hline \multirow{3}{*}{\multicolumn{2}{|c|}{$\begin{array}{l}\text { Base line vs. } 3 \text { weeks } \\
\text { Base line vs. } 6 \text { weeks } \\
3 \text { weeks vs. } 6 \text { weeks }\end{array}$}} & -6.51 & 44.83 & 0.0001 & $\mathrm{~S}$ \\
\hline & & -9.41 & 64.8 & 0.0001 & S \\
\hline & & -2.9 & 13.78 & 0.01 & $\mathrm{~S}$ \\
\hline \multicolumn{6}{|l|}{ Group B: } \\
\hline \multirow{3}{*}{\multicolumn{2}{|c|}{$\begin{array}{l}\text { Base line vs. } 3 \text { weeks } \\
\text { Base line vs. } 6 \text { weeks } \\
3 \text { weeks vs. } 6 \text { weeks }\end{array}$}} & -3.22 & 19.1 & 0.007 & $\mathrm{~S}$ \\
\hline & & -6.43 & 38.16 & 0.0001 & $\mathrm{~S}$ \\
\hline & & -3.21 & 16 & 0.005 & $\mathrm{~S}$ \\
\hline \multicolumn{6}{|c|}{ Between group comparison } \\
\hline & & \multirow[t]{2}{*}{$\mathrm{MD}$} & \multicolumn{2}{|c|}{$p$-value } & Sig. \\
\hline \multicolumn{5}{|l|}{$A$ vs $B$} & \\
\hline \multirow{2}{*}{\multicolumn{2}{|c|}{$\begin{array}{l}\text { Base line } \\
3 \text { weeks }\end{array}$}} & -2.33 & \multicolumn{2}{|c|}{0.19} & S \\
\hline & & 0.96 & & 64 & $\mathrm{~S}$ \\
\hline \multicolumn{2}{|l|}{6 weeks } & 0.65 & \multicolumn{2}{|c|}{0.7} & $\mathrm{~S}$ \\
\hline
\end{tabular}




\begin{tabular}{|c|c|c|c|c|c|}
\hline \multicolumn{3}{|c|}{$\begin{array}{c}\text { Group A } \\
\mathrm{X} \pm \mathrm{SD}\end{array}$} & \multicolumn{3}{|c|}{$\begin{array}{c}\text { Group B } \\
X \pm S D\end{array}$} \\
\hline Base line & 3 weeks & 6 weeks & Base line & 3 weeks & 6 weeks \\
\hline $255.91 \pm 95.22$ & $494.34 \pm 172.77$ & $634.34 \pm 144.21$ & $299.93 \pm 149.31$ & $516.87 \pm 186.27$ & $604.07 \pm 124.38$ \\
\hline \multicolumn{6}{|c|}{ Within group comparison } \\
\hline & & MD & $\%$ of change & $p$-value & Sig. \\
\hline \multicolumn{6}{|l|}{ Group A: } \\
\hline Base line vs. & weeks & -238.43 & 93.16 & 0.0001 & S \\
\hline Base line vs. & weeks & -378.43 & 147.87 & 0.0001 & $\mathrm{~S}$ \\
\hline 3 weeks vs. 6 & veeks & -140 & 28.32 & 0.004 & S \\
\hline \multicolumn{6}{|l|}{ Group B: } \\
\hline Base line vs. & weeks & -216.94 & 72.33 & 0.0001 & S \\
\hline Base line vs. & weeks & -304.14 & 101.4 & 0.0001 & S \\
\hline 3 weeks vs. 6 & veeks & -87.2 & 16.87 & 0.1 & NS \\
\hline \multicolumn{6}{|c|}{ Between group comparison } \\
\hline & & MD & & value & Sig. \\
\hline \multicolumn{6}{|l|}{$A$ vs $B$} \\
\hline Base line & & -44.02 & & .37 & NS \\
\hline 3 weeks & & -22.53 & & .75 & NS \\
\hline 6 weeks & & 30.27 & & .57 & NS \\
\hline
\end{tabular}

\begin{tabular}{|c|c|c|c|c|c|}
\hline \multicolumn{3}{|c|}{$\begin{array}{c}\text { Group A } \\
X \pm S D\end{array}$} & \multicolumn{3}{|c|}{$\begin{array}{c}\text { Group B } \\
\mathrm{X} \pm \mathrm{SD}\end{array}$} \\
\hline Base line & 3 weeks & 6 weeks & Base line & 3 weeks & 6 weeks \\
\hline $16.67 \pm 4.53$ & $20 \pm 5.58$ & $24.4 \pm 4.06$ & $16.35 \pm 4.56$ & $18.46 \pm 5$ & $21.73 \pm 5$ \\
\hline \multicolumn{6}{|c|}{ Within group comparison } \\
\hline & & MD & $\%$ of change & $p$-value & Sig. \\
\hline \multicolumn{6}{|l|}{ Group A: } \\
\hline Base line & & -3.33 & 19.97 & 0.002 & $\mathrm{~S}$ \\
\hline Base line & & -7.73 & 46.37 & 0.0001 & S \\
\hline 3 weeks v & & -4.4 & 22 & 0.0001 & S \\
\hline \multicolumn{6}{|l|}{ Group B: } \\
\hline Base line & & -2.11 & 12.9 & 0.06 & S \\
\hline Base line & & -5.38 & 32.9 & 0.0001 & S \\
\hline 3 weeks v & & -3.27 & 17.71 & 0.007 & NS \\
\hline
\end{tabular}

\begin{tabular}{lccr}
\hline \multicolumn{2}{c}{ Between group comparison } & Sig. \\
\hline & MD & $p$-value & NS \\
\hline vs $B:$ & & & NS \\
Base line & 0.32 & 0.85 & NS \\
3 weeks & 1.54 & 0.46 & \\
6 weeks & 2.67 & 0.14 & \\
\hline X : Mean. & MD : Mean difference. & S : Significant. \\
SD : Standard deviation. & $p$-value: Probability value. & NS: Non significant.
\end{tabular}




\section{Discussion}

This study was designed to investigate the effect of strengthening of hip extensors and ankle plantar flexors in early ACL reconstruction on knee function, hip, knee and ankle muscles strength.

Effect of early hip extensors and ankle plantar flexors training on knee effusion:

There were significant improvement of effusion and these results disagreed with Garrison et al., [18] who found that isolated hip strengthening exercises may not influence early outcome measurements such as patient outcome forms, effusion, pain levels but they may be beneficial for the development of single limb function during the first three months of a rehabilitation program following ACL reconstruction although use same method in assessment of knee effusion.

In support with the current study Balki \& Göktas [19] investigated that early activation of hip muscles in the early rehabilitation of ACLR had provided important improvements in isometric strength of the hip flexor, extensor, abductor, and adductors in addition to leg swelling, pain and knee strength symmetry so postoperative thigh swelling, and knee flexors and extensors weakness as determinants in ACLR-Hip Strength Deficit values were improved with the Activation of hip strengthening exercises [19].

In support to the current study Bynum et al., [20] confirmed the findings of immediate full motion and early weight bearing and strength training of hip muscles reduced the incidence of stiffness and knee effusion.

Effect of early hip extensors and ankle plantar flexors muscles training on knee function:

In support to the current study there was a study that investigated the importance of hip strength in balance and lower limb performances [18]. Baldon et al., [21] also agreed the current study and demonstrated that increased hip strength improved lower extremity kinematics. The findings of current study agree with Omi et al., [22] who demonstrated that a hip-focused injury prevention program demonstrated significant reduction in the incidence of ACL injury or re-injury after ACL reconstruction [22]. The HIP program was designed to progressively enhance hip joint function through jumplanding maneuvers, hip strength training, and balance exercises [22]

The results of the present study were supported by the results of the study by Harput et al., [23] As they revealed the effect of strengthening of hip muscles on hop performance and balance in patients who underwent hamstring tendon ACLR six months before.

In support to the current study Boden et al., [11] demonstrated that the hip, knee, ankle, and foot help absorb forces during landing and deceleration activities. During the normal weightacceptance phase of landing, the hip muscles assist in the absorption of reaction force from the upper body weight, and the ankle and foot help absorb the ground-reaction forces. When the hip, ankle, and foot segments are not effective in synergistically reducing ground-reaction forces, the leg is converted into a 2-segment column, which may be incapable of adequately absorbing the energy from the ground-reaction forces. The lack of motion at the ankle and the exaggerated hip flexion in intervention group compared with control group may indicate that the hip and ankle joints did not absorb sufficient energy in injury situations [11], this support the current study of the additional effect of strengthening of hip extensors and ankle plantar flexors early post ACL reconstruction to minimize load on the knee and improve functional performance.

The results of the current study agreed with Nguyen et al., [24] who demonstrated that the resulting asymmetry of force producing capabilities of the hip muscles during dynamic activities could negatively influence the neuromuscular control of the hip, contributing to altered lower extremity mechanics known to increase the risk of ACL injuries and re-injuries after ACL reconstruction. In contrast to the results of the current study Risberg et al., [25] there were small differences between the neuromuscular training program and the strength training program, the neuromuscular program was superior to the strength program(The strength program consisted mainly of Strengthening exercises of the lower-extremity muscles, with emphasis on the quadriceps femoris, hamstring, gluteal muscles, and gastrocnemius) in improving knee function after ACL reconstruction but did not give any information related to muscle power and effusion [25]. Subjects who developed pain, swelling underwent treatments until these impairments were resolved.

In contrast to the results of the current study to date, there are no prospective cohort studies addressing hip strength as a potential risk factor for ACL injury or re-injury after ACL reconstruction that addressed that hip strength has no additional effect after ACL reconstruction [26] and this had confirmed by Barber \& Noyes [27] the risk of a 
noncontact ACL injury or re-injury after ACL reconstruction include decreased hip and knee flexion and this disagreed with Khayambashi et al., [28] that investigated that a significant relationship does exist between baseline hip strength and future noncontact ACL injury status or re-injury after ACL reconstruction. Specifically, increased hip strength had a protective effect against future injury (or diminished strength increased injury risk), and this disagreed with Boden et al., [11] who stated that Initial ground contact flatfooted or with the hindfoot, knee abduction and increased hip flexion may be risk factors for anterior cruciate ligament injury or re injury after ACL reconstruction [11]

In contrast to results of the current study Leppänen et al., [29] investigated that a landing strategy that includes hip extension and knee extension may increase the risk of ACL injury in young female team-sport players. So hip and knee flexion produce soft landings might reduce knee loading and ACL injury risk and this disagreed with the results of the current study that concentrated on the strengthening of hip extensors to improve functional performance and prevent re-injury after ACL reconstruction.

In contrast with the results of the current study Hooper et al., [30] designed a study to assess the biomechanical differences in knee function before and after physical therapy based on either open or closed kinetic chain exercises of the hip and knee extensor muscles and studied in a gait analysis laboratory 2 weeks after ACL reconstruction surgery, they found that there was no significant improvement related to functional performance in the early period in the 6 weeks after ACL reconstruction and this may be due to Plantar flexor resistance exercise was excluded from this study and this differed from the current study that used plantar flexors strengthening combined with hip extensors strengthening. Hooper et al., [30] also used gait analysis laboratory to assess gait but the current study used WOMAC and Timed up and Go test to asses function.

The results of the current study disagreed with Elias et al., [31] demonstrated that applying the soleus and gastrocnemius muscle forces together tended to translate the tibia anteriorly with respect to the femur and this was similar to another study in which ACL strain was measured while different muscles were activated, showed that the gastrocnemius acts as an ACL antagonist [32]. The anterior translations produced by applying a gastrocnemius force was unexpected finding in which combined loading of the soleus and gastrocnemius produced tibial translations similar to loading the gastrocnemius alone to act as antagonists to ACL [32]

In support to the current study Shelbourne \& Nitz and Kramer et al., [33,34] observed that functional performance and knee extensors torque returned much more quickly after hip extensors strengthening but additional emphasis should be directed to strengthening knee flexors and extensors using both concentric and eccentric muscle actions.

Effect of early hip extensors and ankle plantar flexors muscles training on hip, knee, and ankle muscles strength:

The findings of present study agreed with $\mathrm{Ny}$ land et al., [35] that observed that hip extensors (including the hamstring muscle group) and ankle plantar flexor activation may compensate impaired knee extensor torque in the early period after ACL reconstruction and they act as weight acceptance during landing as the hip muscles assist in the absorption of reaction force from the upper body weight, and the ankle and foot help absorb the ground-reaction forces [11]. In a normal landing pattern, the gastrocnemius-soleus complex contracts to help absorb ground-reaction forces [36]

Bell et al., [37] demonstrated that hip strength was higher in individuals with quadriceps strength asymmetry after ACL reconstruction and the most important finding of this study was that patients in the low quadriceps group had greater hip extension strength in both limbs compared with the high quadriceps and control groups and the results of this study agreed with the current study and expand our understanding of the long-term consequences of ACL reconstruction and this is the reason to develop strategies that can be implemented early in the rehabilitation process to address quadriceps strength asymmetry [37]. The results of this modeling study demonstrated that the gluteus maximus and soleus were muscles that had the greatest potential to compensate for a reduction in quadriceps weakness [33]. Specifically, the gluteus maximus was more likely to compensate in the landing phase of foot strike and acts to slow the body during gait [37].

Findings of present study supported by Thompson et al., [38] that confirmed that the low quadriceps group had greater bilateral hip extensor strength compared with the high quadriceps and control groups and these results agreed with previous research that modeled quadriceps weakness in healthy individuals. 
A variety of reasons may exist as to why a patient with poor quadriceps strength may develop increased hip strength over time. Several studies have observed patients with ACL reconstruction utilize proximal and distal strategies during squatting [39], hopping [40,41], and gait [42,43]. Noehren et al., [43] observed that patients with ACL reconstruction had smaller hip flexion angles during walking and tended to utilize larger hip extensor moments. Altered kinematics and kinetics occur bilaterally and could theoretically result in increased hip muscle utilization in the short term that may translate into increased strength over time.

In contrast to the results of the current study Dingenen et al., [44] showed significantly delayed muscle activation onset times not only at muscles surrounding the operated knee joint, but also at the gluteal muscles during the transition from double leg stance to single-leg stance in subjects with ACL reconstruction compared to non-injured control subjects, despite completion of rehabilitation. Furthermore, no significant different muscle activation onset times were found between the operated and non-operated leg in the ACLR group. These findings provide evidence that neuromuscular control deficits after ACL reconstruction are not limited to the operated knee joint, and indirectly support the role of Central Nervous System adaptations after ACL reconstruction. Clinicians should focus on relearning anticipatory multi-segmental neuromuscular strategies after ACL reconstruction based on Central Nervous System re-education approaches and this disagreed with the current study that had provided early return and activation of muscles power of hip extensors, ankle plantar flexors and knee extensors torque.

The findings of the current study agreed with Harput et al., [45] investigated that during different phases of weight bearing tasks between individuals who had undergone ACLR and healthy controls and found that Gluteal muscles activation were variable. The individuals who had undergone ACLR demonstrated lower Gluteal muscles activation compared to healthy individuals so Gluteal muscles activation should be evaluated in persons who have undergone ACLR and consideration should be given for including Gluteal muscles activation exercises as part of post ACLR rehabilitation.

In support to the results of the current study Thomas et al., [10] investigated that the ACLinjured participants presented with hip-extensor, adductor, and ankle-plantar-flexor weakness that appeared to be countered during postoperative rehabilitation. Improving rehabilitation strategies to better target this weak muscles.

\section{Conclusion:}

Addition of strengthening of hip extensors and plantar flexors to traditional accelerated protocol added more beneficial outcomes in relation to function after 6 weeks.

\section{References}

1- WILLIAMS G., CHMIELEWSKI T., RUDOLPH K., BUCHANAN T. and SNYDER M.: Dynamic knee stability current theory and implications for clinicians and scientists. J. Orthop. Sports Phys. Ther., 31: 546-66, 2001.

2- RISBERG M., LEWEK M. and SNYDER-MACKLER L.: A systematic review of evidence for anterior cruciate ligament rehabilitation: How much and whattype? Phys. Ther. in Sports, (3): 125-45, 2004.

3- STERGIOU N., RISTANIS S., MORAITI C. and GEORGOULIS A.: Tibial rotation in anterior cruciate ligament (ACL)-deficient and ACL-reconstructed knees. Sports Medicine, 37: 601-13, 2007.

4- CHU C.R., BEYNNON B.D., BUCKWALTER J.A., et al.: Closing the gap between bench and bedside research for early arthritis therapies (EARTH): Report from the AOSSM/NIH U-13 Post-Joint Injury Osteoarthritis Conference II. Am. J. Sports Med., 39: 1569-1578, 2011.

5- QUATMAN C.E., KIAPOUR A., MYER G.D., et al. Cartilage pressure distributions provide a footprint to define female anterior cruciate ligament injury mechanisms. Am. J. Sports Med., 39: 1706-1713, 2011.

6- HEWETT T.E., Di STASI S.L. and MYER G.D.: Current concepts for injury prevention in athletes after anterior cruciate ligament reconstruction. Am. J. Sports Med., 41: 216-224, 2013.

7- JARAMILLO J., WORRELL T.W. and INGERSOLL C.D.: Hip isometric strengthfollowing knee surgery. J. Orthop. Sports Phys. Ther., 20 (3): 160-165, 1994.

8- HIEMSTRA L.A., GOFTON W.T. and KRIELLAARS D.J.: Hip strength following hamstring tendon anterior cruciate ligament reconstruction. Clin. J. Sport Med., 15 (3): 180-182, 2005

9- KARANIKAS K., ARAMPATZIS A. and BRUGGEMANN G.P.: Motor task and musclestrength followed different adaptation patterns after anterior cruciateligament reconstruction. Eur. J. Phys. Rehabil Med., 45 (1): 37 45, 2009.

10- THOMAS A.C., VILLWOCK M., WOJTYS E.M. and PALMIERI-SMITH R.M.: Lower extremity muscle strength after anterior cruciate ligament injury and reconstruction. J. Athletic Training, 48: 610-20, 2013.

11-BODEN B.P., TORG J.S., KNOWLES S.B. and HEWETT T.E.: Video analysis of anterior cruciate ligament injury abnormalities in hip and ankle kinematics. Am. J. Sports Med., 37: 252-59, 2009.

12-MAJIMA T., YASUDA K., TAGO H., et al.: Rehabilitation after hamstring anterior cruciate ligament reconstruction. Clin. Orthop., 397: 370-80, 2002.

13- SHAW T., CHIPCHASE L. and WILLIAMS M.: A users guide to outcome measurement following reconstruction. Phys. Ther. Sport, 5: 57-67, 2004. 
14- DeHAVEN K., COSGAREA A. and SEBASTIANELLI W.: Arthrofibrosis of the knee following ligament surgery. Instr. Course Lect, 52: 369-81, 2003.

15- GOLDBLATT J., FITZSIMMONS S., BALK E., et al.: Reconstruction of the anterior cruciate ligament, metaanalysis of patellar tendon versus hamstring tendon autograft. Arthroscopy, 21: 791-03, 2005.

16-MADDISON R., PRAPAVESSIS H. and CLATWORTHY M.: Modelling and rehabilitation following anterior cruciate ligament reconstruction. Ann. Behav. Med., 31: 8998, 2006.

17- PINCZEWSKI L., LYMAN J., SALMON L., et al.: A 10year comparison of anterior cruciate ligament reconstructions with hamstring tendon and patellar tendon autograft, a controlled, prospective trial. Am. J. Sports Med., 35: 564-74, 2007.

18- GARRISON J., BOTHWELL J., COHEN K., CONWAY J.: Effects of hip strengthening on early Outcomes following anterior cruciate Ligament reconstruction. Int. J. Sports Phys. Ther., 9: 157-67, 2014.

19- BALKI S. and GÖKTAS H.E.: Short-Term Effects of the Kinesio Taping ${ }^{\circledR}$ on Early Postoperative Hip Muscle Weakness in Male Patients With Hamstring Autograft or Allograft Anterior Cruciate Ligament Reconstruction. J. Sports Rehabil, 1-21, 2017.

20- BYNUM E.B., BARRACK R.L. and ALEXANDER A.H.: Open versus closed chain kinetic exercises after anterior cruciate ligament reconstruction: A prospective randomized study. The American Journal of Sports Medicine, 23 (4): 401-406, 1995.

21- BALDON R.M., PIVA S.R., SCATTONE SILVA R. and SERRAO F.V.: Evaluating eccentric hip torque and trunk endurance as mediators of changes in lower limb and trunk kinematics in response to functional stabilization training in women with patellofemoral pain. Am. J. Sports Med., 43 (6): 1485-1493, 2015.

22- OMI Y., SUGIMOTO D., KURIYAMA S., KURIHARA T., MIYAMOTO K., YUN S. and HIROSE N.: Effect of hip-focused injury prevention training for anterior cruciate ligament injury reduction in female basketball players: a 12-year prospective intervention study. Am. J. Sports Med., 46 (4): 852-861, 2018.

23- HARPUT G., ULUSOY B., OZER H., BALTACI G. and RICHARDS J.: External supports improve knee performance in anterior cruciate ligament reconstructed individuals with higher kinesiophobia levels. Knee, 23 (5): 807-812, 2016.

24- NGUYEN A.D., ZUK E.F., BAELLOW A.L., PFILE K.R., DISTEFANO L.J. and BOLING M.C.: Longitudinal Changes in Hip Strength and Range of Motion in Female Youth Soccer Players: Implications for ACL Injury, A Pilot Study. J. Sports Rehabil, 26 (5): 358-364, 2017.

25- RISBERG M.A., HOLM I., MYKLEBUST G. and ENGEBRETSEN L.: Neuromuscular training versus strength training during first 6 months after anterior cruciate ligament reconstruction: A randomized clinical trial. Phys. Ther., 87 (6): 737-50, 2007

26- STEFFEN K., NILSTAD A., KRISTIANSLUND E.K., MYKLEBUST G., BAHR R. and KROSSHAUG T.: Association between lower extremity muscle strength and noncontact ACL injuries. Med. Sci. Sports Exerc., 208289, 2016.
27- BARBER S.D. and NOYES F.R.: Effect of Fatigue Protocols on Lower Limb Neuromuscular Function and Implications for Anterior Cruciate Ligament Injury Prevention Training: A Systematic Review. Am. J. Sports Med., 45 (14): 3388-3396, (2017.

28- KHAYAMBASHI K., GHODDOSI N., STRAUB R. K. and POWERS C.M. (). Hip muscle strength predicts noncontact anterior cruciate ligament injury in male and female athletes: A prospective study. Am. J. Sports Med., 44 (2): 355-361, 2016.

29- LEPPÄNEN M., PASANEN K., KROSSHAUG T., KANNUS P., VASANKARI T., KUJALA U.M. and PARKKARI J.: Sagittal Plane Hip, Knee, and Ankle Biomechanics and the Risk of Anterior Cruciate Ligament Injury: A Prospective Study. Ortho. J. Sports Med., 5 (12): 1-6, 2017.

30- HOOPER D.M., MORRISSEY M.C., DRECHSLER W., MORRISSEY D. and KING J.: Open and closed kinetic chain exercises in the early period after anterior cruciate ligament reconstruction: Improvements in level walking, stair ascent, and stair descent. Am. J. Sports Med., 29 (2): 167-174, 2001

31- ELIAS J.J., FAUST A.F., CHU Y.H., CHAO E.Y. and COSGAREA A.J.: The soleus muscle acts as an agonist for the anterior cruciate ligament: an in vitro experimental study. Am. J. Sports Med., 31(2), 241-246, 2003.

32- FLEMING B.C., RENSTROM P.A., OHLEN G., et al.: The gastrocnemius muscle is an antagonist of the anterior cruciate ligament. J. Orthop. Res., 19: 1178-1184, 2001.

33- SHELBOURNE K.D. and NITZ P.: Accelerated rehabilitation after anterior cruciate ligament reconstruction. Am. J. Sports Med., 18 (3): 292-299, 1990.

34- KRAMER J., NUSCA D., FOWLER P. and WEBSTERBOGAERT S.: Knee flexor and extensor strength during concentric and eccentric muscle actions after anterior cruciate ligament reconstruction using the semitendinosus tendon and ligament augmentation device. Am. J. Sports Med., 21 (2): 285-291, 1993.

35- NYLAND J., BRAND E. and FISHER B.: Update on rehabilitation following ACL Reconstruction. Sports Med., 1: $151-166,2010$

36- HEWETT T.E., MYER G.D. and FORD K.R.: Anterior cruciate ligament injuries in female athletes part 1, mechanisms and risk factors. Am. J. Sports Med., 34: 299-11, 2006.

37- BELL D.R., TRIGSTED S.M., POST E.G. and WALDEN C.E.: Hip Strength in Patients with Quadriceps Strength Deficits after ACL Reconstruction. Med. Sci. Sports Exerc., 48 (10): 1886-1892, 2016.

38- THOMPSON J.A., CHAUDHARI A.M., SCHMITT L.C., et al.: Gluteus maximus and soleus compensate for simulated quadriceps atrophy and activation failure during walking. J. Biomech., 46 (13): 2165-72, 1892, 2013.

39- BELL D.R., KULOW S.M., STIFFLER M.R., et al.: Squatting mechanics in people with and without anterior cruciate ligament reconstruction: The influence of graft type. Am. J. Sports Med., 42 (12): 2979-87, 2014.

40- OBERLANDER K.D., BRUGGEMANN G.P., HOHER J., et al.: Altered landing mechanics in ACL-reconstructed patients. Med. Sci. Sports Exerc., 45 (3): 506-13, 2013. 
41- OBERLANDER K.D., BRUGGEMANN G.P., HOHER J., et al.: Knee mechanics during landing in anterior cruciate ligament patients: A longitudinal study from preto 12 months post-reconstruction. Clin. Biomech., 29 (5): 512-7, 2014

42- JONIN P.Y., NOEL A., TREBON P., et al.: Towards a left MTL specialization for arbitrary-associative learning? A multiple-case study. Behav Neurol., 26 (3): 211-3, 2013.

43- NOEHREN B., WILSON H., MILLER C., et al.: Longterm gait deviations in anterior cruciate ligamentreconstructed females.Med. Sci. Sports Exerc., 45 (7): 1340-7, 2013

44- DINGENEN B., JANSSENS L., LUYCKX T., CLAES S., BELLEMANS J. and STAES F.F.: Lower extremity muscle activation onset times during the transition from double-leg stance to single-leg stance in anterior cruciate ligament injured subjects. Hum. Mov. Sci., 44: 234-245 2015 .

45- HARPUT G., HOWARD S. and MATTACOLA C.: Comparison of muscle activation levels between healthy individuals and persons who have undergone anterior cruciate ligament reconstruction during different phases of weight-bearing exercises. J. Orthop. Sports Phys. Ther., 46 (11): 984-992, 2016.

46- De CARLO S., SHELBOURNE D., McCARROLL R. and RETTIG C.: Traditional versus accelerated rehabilitation following ACL reconstruction: A one-year followup. J. Orthop. Sports Phys. Ther., 15: 309-16, 1992.

47- KISNER C. and COLBY L.A.: Ther. Exer: Foundations and Techniques. Philadelphia, PA: F.A. Davis, p 66-104, 2007.

\section{Appendix I}

\section{Western Ontario McMaster Index}

0 : Not any.

1: A little.

2: Moderate.

3: Important.

4: Very important - extreme.

\section{WOMAC index}

$P$ Subscale:

How much pain do you have?

1: Walking on flat surface.

2: Going up or down stairs.

3: At night while in bed.

4: Sitting or lying

5: Standing upright.

S Subscale:

How severe is your stiffness?

1: After first wakening in the morning.

2: After sitting lying or resting later in the day.

PF Subscale:

What degree of difficulty do you have?

1: Descending stairs.

2: Ascending stairs.

3: Rising from sitting.

4: Standing.

5: Bending to floor.

6: Walking on flat.

7: Getting in / out of car.

8: Going shopping.

9: Putting on socks/stockings.

10: Rising from bed.

11: Taking off socks/stockings.

12: Lying in bed.

13: Getting in/off bath.

14: Sitting.

15: Getting on/off toilet.

16: Heavy domestic duties.

17: Light domestic duties.

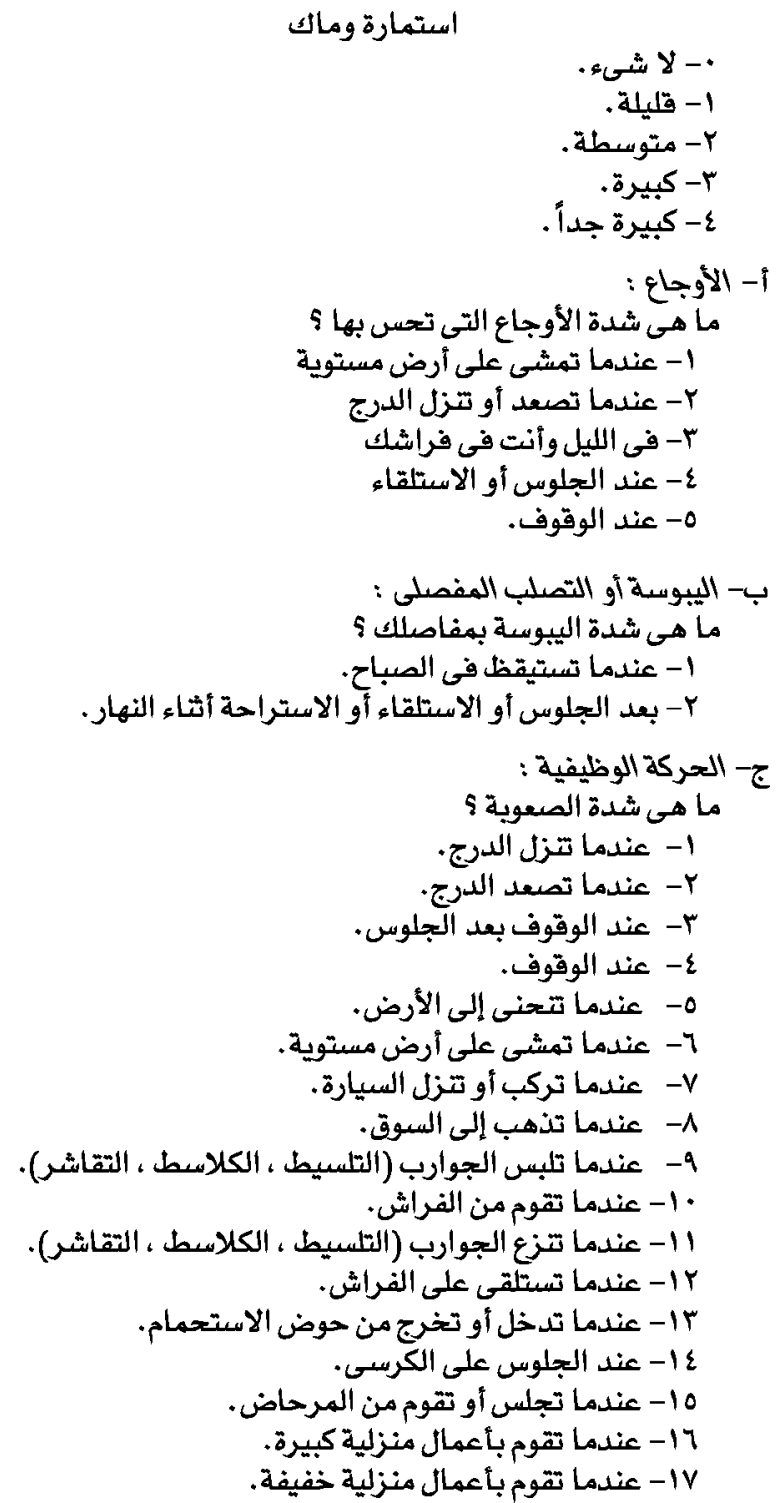

ما هي شـدة الأوجاع التى تحس بها

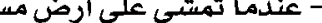

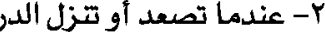

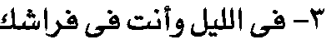
0- عند الوقوف. عند الولون.

ب- اليبوسة أو التصلب المفصلى :

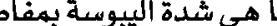

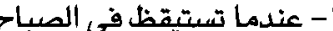
ج- العركة الوظيفية : ما هي شديدة الصعوية ؟ - عندما تتزل الدرج. Y Y - عندما تصعد الدرج الدرج. - عند الوقوف.

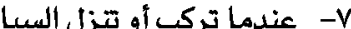

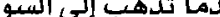

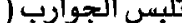

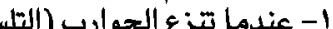




\section{Appendix II \\ Traditional accelerated program De Carlo et al., [46]:}

1st day Post-Op.:

Compression \& Cold to prevent hemarthrosis.

Gently maintains available ROM (0-90).

Electreical stimulation.

Discharge day to day 7.

Bedrest except for bathroom.

- Heel prop extension exercises.

- Flexion exercises

- SLR

- Quad Sets

Cryo/Cuff worn continually except during exercises to prevent a hemarthrosis.

\section{2nd Week Postoperative:}

Full hyperextension is achieved by:

1- Heel Prop Exercise

2- Prone Hang Exercise

3- Hamstring Stretching Exercise.

Flexion 110 degrees is is isaccomplished through:

1- Wall Slide Exercise.

2- Heel slide exercise.

3- Hamstring curl exercise.

4- Multiple angle hamstring isometric exercise.

\section{Gait training:}

Subjects ambulated with 2 crutches for the first 2 weeks postoperatively.

- The heel-to-toe gait pattern was taught to the subject.

Quadriceps muscle leg control is enhanced by:

1- Quadriceps setting exercise.

2- SLR exercises.
3- Short-arc quadriceps exercise.

4- Quadriceps isometrics with the knee at 90 degrees.

Weeks 3-6 Postoperative:

- Full ROM in the knee is achieved with:

1- Continued Heel Slide Exercise

2- Exercise on a Stationary Bicycle

3- Kneeling Stretch.

Normal gait pattern was gradually achieved as following:

Subjects ambulated with one crutch for the 2 nd 2 weeks postoperatively, and finally discontinued crutch use by 4 weeks postoperatively.

Maintaining a normal gait pattern and avoiding the habit of limping was emphasized.

- All exercises previously described will be continued, and weighted resistance was applied from the third week beginning with $1 \mathrm{lb}$. and progressing by $1 \mathrm{lb}$. per week.

Strengthening exercises of hip and ankle plantar flexor performed for 10 repetitions with $3 \mathrm{sec}$ rest between the repetitions for 2 sets then the patient had a rest for 1 minute after each set. Each patient was trained at $60 \%$ of 10 -repetition maximum (the amount of weight that could be lifted and lowered through available range of motion exactly 10 times). A new 10 repetition maximum will be established at the end of a week of training. Kisner and Colby [47].

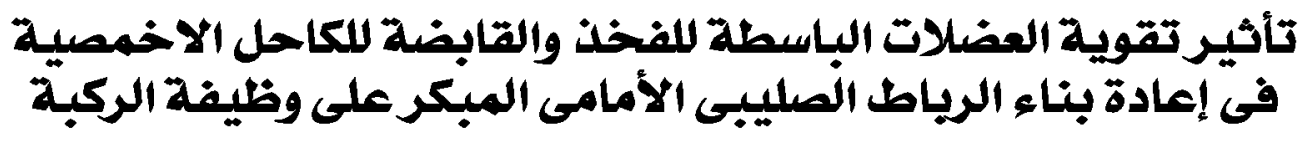

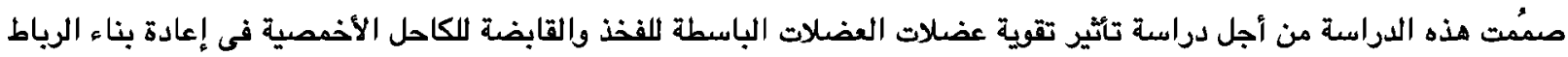

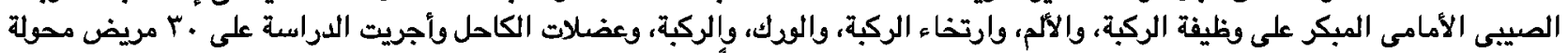

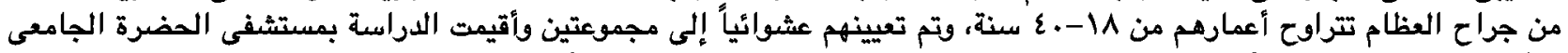

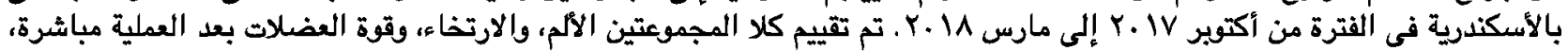

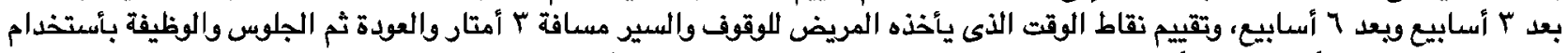

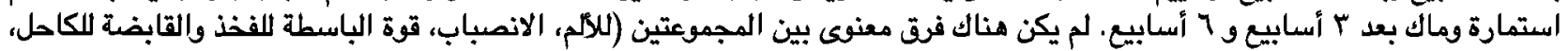

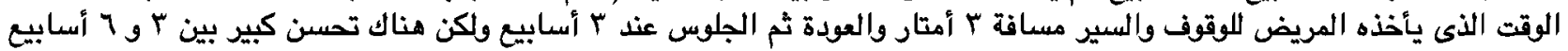

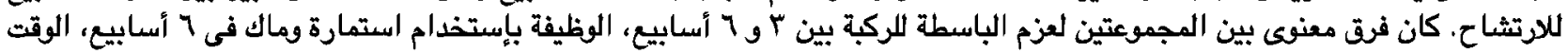

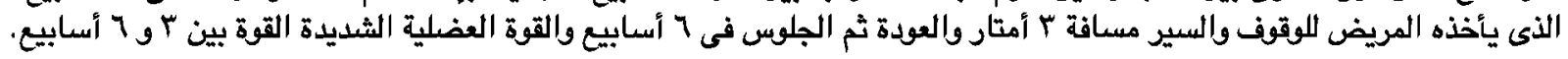

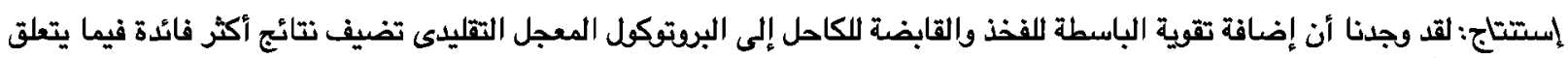

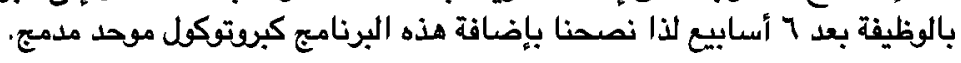

